\title{
Clinical implications of hypertrophic cardiomyopathy associated with mutations in the $\alpha$-tropomyosin gene
}

Keiko Yamauchi-Takihara, Chieko Nakaijma-Taniguchi, Hideo Matsui, Yasushi Fujio, Keita Kunisada, Seiki Nagata, Tadamitsu Kishimoto

\begin{abstract}
Objective-The disease-bearing genes for hypertrophic cardiomyopathy (HCM) in HCM families have been identified as the $\beta$-myosin heavy chain, $\alpha$-tropomyosin, and cardiac troponin $T$ genes. Three HCM kindreds with three distinct point mutations in the $\alpha$-tropomyosin gene had extensive clinical evaluations.

Design and results-Single-strand conformation polymorphism gel analysis of polymerase chain reaction amplified products was used to capture each of the nine exons from the $\alpha$-tropomyosin gene to identify mutations in 60 familial HCM patients. Two missense mutations in exon 2 (Ala63Val and Lys70Thr) and one missense mutation in exon 5 (Asp175Asn) were found in three unrelated HCM kindreds. These kindreds were the subject of clinical, electrocardiographic and echocardiographic studies. The morphological appearance of HCM was similar in the three kindreds. All the patients had severe hypertrophy of the left ventricle with asymmetrical septal hypertrophy during the early stage of the disease, which gradually progressed to dilatation of the left ventricle. Moreover, these kindreds showed similar disease penetrance, age of onset, and incidence of premature sudden death. The disease in these kindreds was severe and resulted in frequent sudden deaths.
\end{abstract}

Conclusions-Among Japanese patients with familial HCM mutations in the $\alpha$ tropomyosin gene are not as rare as reported, accounting for about $5 \%$ of all cases. These mutations are characterised by hypertrophy of the left ventricle which then progresses to dilatation and a high incidence of sudden or disease-related death.

(Heart 1996;76:63-65)

Keywords: familial hypertrophic cardiomyopathy; $\alpha$ tropomyosin gene mutation; prognosis; phenotypic analysis

Familial hypertrophic cardiomyopathy (HCM) varies in its clinical manifestations and is genetically heterogeneous. Linkage analysis has shown that in more than half of the kindreds a disease-bearing gene is located on chromosomes $1,11,14$, and $15 . .^{1-4}$

Recently, two disease-causing mutations were identified in exon 5 of the $\alpha$-tropomyosin gene in three European HCM kindreds. ${ }^{5-7}$ Studies of mutations in the $\alpha$-tropomyosin gene in 50 Japanese familial HCM patients also revealed mutations in exon 2 and exon 5 of the $\alpha$-tropomyosin gene. ${ }^{8}$ Studies of another 10 Japanese familial HCM patients identified a novel mutation which is associated with the substitution of lysine for threonine at position 70 (Lys70Thr) in exon 2 of the $\alpha$-tropomyosin gene. This mutation has not been found in the genomes of unaffected individuals.

In this study, we present evidence of the similarity of the clinical manifestations of HCM associated with $\alpha$-tropomyosin gene mutations. These findings indicate that the disease-bearing gene can influence clinical expression.

\section{Patients and methods}

CLINICAL STUDIES

Clinical evaluation of family members was performed with the aid of their medical history, a physical examination, a 12 lead electrocardiogram, and a cross sectional echocardiogram. The maximum thickness of the left ventricular wall was measured in diastole in the region of the greatest hypertrophy. A diagnosis of HCM was based on a maximum left ventricular wall thickness of at least $13 \mathrm{~mm}$ and absence of the causes of ventricular hypertrophy as specified by Maron's criteria. ${ }^{9}$

A venous blood sample for extraction of DNA was obtained after informed consent.

\section{Detection of mutations}

Screening for mutations was performed with a previously described technique. ${ }^{10}$ Individual exons of the $\alpha$-tropomyosin gene were amplified from genomic DNA by the polymerase chain reaction single-strand conformation polymorphism (PCR-SSCP) method. ${ }^{8}$ The presence of mutations was determined in the PCR-amplified DNA of each individual by cycle sequencing using the Model 373A DNA Sequencing System (Applied Biosystems Japan, Tokyo, Japan).

Mutations are denoted by the normal amino acid residue and its position, followed by the mutant amino acid (for example, Lys70Thr).

\section{Results}

The $\alpha$-tropomyosin sequence was analysed in three probands with HCM who presented different patterns as identified by PCR-SSCP gel analysis. Two of these sequence changes, 
Comparison of clinical findings in individuals affected in the three kindreds

\begin{tabular}{|c|c|c|c|c|c|c|c|c|c|}
\hline & \multirow[b]{2}{*}{$\begin{array}{l}\text { Pedigree } \\
\text { no }\end{array}$} & \multirow[b]{2}{*}{ Age/sex } & \multirow[b]{2}{*}{$\begin{array}{l}\text { NYHA } \\
\text { class }\end{array}$} & \multicolumn{2}{|l|}{$E C G$} & \multirow[b]{2}{*}{ Syncope } & \multicolumn{2}{|c|}{ Echocardiogram } & \multirow[b]{2}{*}{ Clinical event } \\
\hline & & & & $L V H / S T^{\star}$ & Arrhythmia & & $\underset{(\mathrm{mm})}{I V S / L V W T}$ & $\begin{array}{l}\text { LVDd/Ds } \\
(\mathrm{mm})\end{array}$ & \\
\hline $\begin{array}{l}\text { Family } 1 \\
\text { (kindred 17) } \\
\text { (Ala63Val) }\end{array}$ & $\begin{array}{l}\text { I-2 } \\
\text { II }-3\end{array}$ & $\begin{array}{l}57 / \mathrm{F} \\
36 / \mathrm{M}\end{array}$ & $\begin{array}{l}\text { IV } \\
\text { II }\end{array}$ & $\begin{array}{l}+ \\
+\end{array}$ & PVCs, VT & $\overline{+}$ & $\begin{array}{l}8 / 15 \\
20 / 10\end{array}$ & $\begin{array}{l}59 / 55 \\
53 / 40\end{array}$ & CHF death \\
\hline $\begin{array}{l}\text { Family } 2 \\
\text { (kindred 7) } \\
\text { (Asp175Asn) }\end{array}$ & $\begin{array}{l}\text { II-4 } \\
\text { II-5 } \\
\text { III-1 }\end{array}$ & $\begin{array}{l}63 / \mathrm{F} \\
48 / \mathrm{F} \\
38 / \mathrm{F}\end{array}$ & $\begin{array}{l}\text { III } \\
\text { II } \\
\text { I }\end{array}$ & $\begin{array}{l}+ \\
+ \\
-\end{array}$ & $\begin{array}{l}\text { af/VT } \\
-\end{array}$ & \pm & $\begin{array}{l}22 / 8 \\
9 / 9 \\
15 / 8\end{array}$ & $\begin{array}{l}41 / 28 \\
72 / 55 \\
48 / 32\end{array}$ & $\begin{array}{l}\text { Episode of sustained VT } \\
\text { CHF, sudden death }\end{array}$ \\
\hline $\begin{array}{l}\text { Family } 3 \\
\text { (kindred 4) } \\
\text { (Lys70Thr) }\end{array}$ & $\begin{array}{l}\text { II-1 } \\
\text { II-3 } \\
\text { II-6 }\end{array}$ & $\begin{array}{l}59 / \mathrm{F} \\
50 / \mathrm{F} \\
45 / \mathrm{M}\end{array}$ & $\begin{array}{l}\text { I } \\
\text { III } \\
\text { I }\end{array}$ & $\begin{array}{l}+ \\
+ \\
+\end{array}$ & $\begin{array}{l}\text { PVCs, VT } \\
\text { PVCs, VT } \\
\text { PVCs }\end{array}$ & E & $\begin{array}{l}22 / 12 \\
15 / 10 \\
22 / 12\end{array}$ & $\begin{array}{l}44 / 29 \\
60 / 40 \\
57 / 33\end{array}$ & $\mathrm{CHF}$, sudden death \\
\hline
\end{tabular}

${ }^{\star}$ By voltage criteria and/or ST segment abnormalities.

NYHA class, New York Heart Association functional class; LVH, left ventricular hypertrophy; IVS, interventricular septum; LVWT, left ventricular wall thickness; Dd, diastolic dimension; Ds, systolic dimension; PVC, paroxysmal ventricular contraction; af, atrial fibrillation; VT, ventricular tachycardia; CHF, congestive heart failure.

Ala63Val and Asp175Asn, which have been described previously as disease-causing mutations, were seen in families 1 and 2 , respectively. ${ }^{8}$ The Asp175Asn mutation was

Pedigrees of three families (1, 2, and 3) with atropomyosin gene mutations. Individuals are identified by pedigree number. Squares and circles indicate males and females, respectively. Open, closed, and hatched symbols indicate unaffected, affected, and suspected, respectively. The proband in the pedigree is indicated by the arrow. Symbols representing those who have died are crossed through.

\section{Family 1 (kindred 17)}

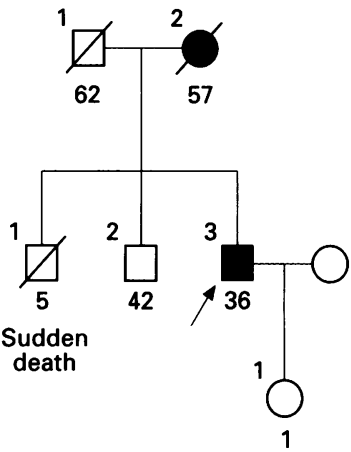

Family 2 (kindred 7)

I

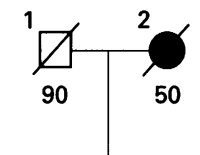

II

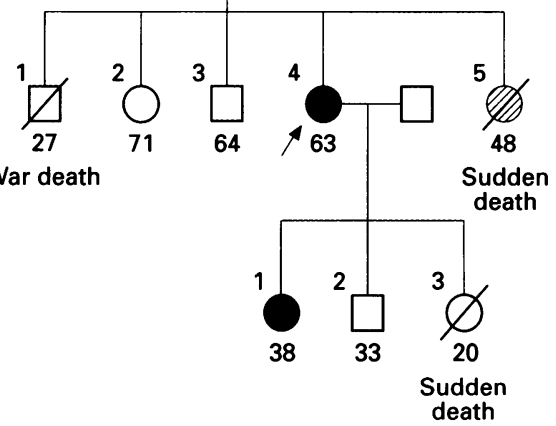

Family 3 (kindred 4)

I

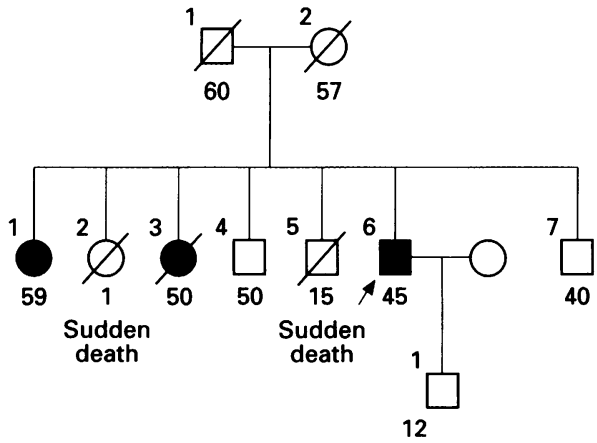

identical to the mutation recently found in two European kindreds. ${ }^{56}$ In addition, one novel missense mutation was identified in family 3 , namely Lys70Thr. This $\alpha$-tropomyosin sequence also exhibited the features characteristic of disease-causing mutations and thus does not constitute a silent polymorphism.

All available members of families 1,2 , and 3 were clinically evaluated. Clinical findings for these individuals are summarised in the table. Two members of family 1 , the proband II-3 and his mother I-2, were diagnosed as HCM (figure) on the basis of left ventricular hypertrophy determined by echocardiogram. Individual I-2 died two years ago with symptoms of congestive heart failure and was diagnosed post mortem as having dilated-phase HCM.

Three members of family 3 , the proband II6 and his two sisters II-1 and II-3, were diagnosed as having HCM (figure). The most recent echocardiogram of the proband (II-6) and his elder sister (II-1) showed a mildly dilated left ventricle with frequent premature ventricular contractions or episodes of ventricular tachycardia. In 1985, the thicknesses of the proband's interventricular septum and left ventricular wall were $22 \mathrm{~mm}$ and $12 \mathrm{~mm}$ respectively, but after 10 years of observation they had decreased to $12 \mathrm{~mm}$ and $10 \mathrm{~mm}$, respectively. Individual II-3, who showed severe symptoms of congestive heart failure, died suddenly at the age of 50 and was diagnosed post mortem as having dilated-phase HCM. The proband's elder brother also died suddenly at the age of 15 , probably from lethal arrhythmia. Both of the proband's parents were dead.

Three members of family 2 , the proband II-4, her mother I-2, and her daughter III-1, were diagnosed as HCM (figure). Both individuals II-5 and III-3 died suddenly and the proband also had frequent sustained ventricular tachycardia. The proband was diagnosed by echocardiogram in 1978, when she was 40 years old, as having typical asymmetrical septal hypertrophy. Thereafter, she had symptoms of congestive heart failure with frequent ventricular tachycardia. Her most recent echocardiogram showed a mildly dilated left ventricle. II-5 was admitted to hospital with symptoms of congestive heart failure. Her echocardiogram showed a severely dilated left 
ventricle and left ventriculography showed an ejection fraction of $21 \%$. A necropsy was not performed and previous echocardiographic data were not available.

\section{Discussion}

We have reported a novel mutation in the $\alpha$ tropomyosin gene that causes HCM. This mutation, and two previously described mutations, ${ }^{8}$ characteristically produced moderate hypertrophy that in some instances seemed clinically unimportant. Despite this, the HCM caused by these mutations was associated with a high incidence of sudden or disease-related death. In mutations in cardiac troponin $T$ the severity of cardiac hypertrophy does not reflect the risk of sudden or disease-related death. ${ }^{7}$ The two cases reported in this study are particularly good examples of this dissociation: individual II-5 in family 3 and individual III-3 in family 2 , both had normal findings on clinical evaluation, but nevertheless died suddenly. Moreover, individuals I- 2 and II- 3 in family 1 , II- 1 , II-3 and II- 6 in family 3 , and II-4 and II5 in family 2 were diagnosed as having dilatedphase HCM (table). We have already reported evidence of progression of hypertrophic cardiomyopathy to a dilated phase ${ }^{11}$ and the association of this phase with abnormal thallium perfusion and cardiac enzymes. ${ }^{12}$

Five of 50 Japanese patients with HCM have been shown to have a mutation in the $\beta$ myosin heavy chain gene. Those with glycine deletion in exon 3 had a good prognosis; there were no premature sudden deaths or diseaserelated deaths within the families. ${ }^{10}$ In these patients with $\beta$-myosin heavy chain gene mutation there was usually considerable left ventricular hypertrophy.

Three of six known $\alpha$-tropomyosin gene mutations involve independent occurrences of the same nucleotide alteration. This may reflect an increased tendency for this particular residue to mutate. Though the mutation identified in exon 5 (Asp175Asn) of the $\alpha$ tropomyosin gene occurs near the calciumdependent troponin $\mathrm{T}$ binding domain, ${ }^{5}$ the function of exon 2 remains unclear. However, both mutations in exon 2 of the $\alpha$ tropomyosin gene occur near one of two putative regions of interaction with troponin $T .{ }^{13}$ Both the mutation of the alanine residue at codon 63 and of the lysine residue at codon 70 have been identified as highly conserved amino acids. ${ }^{14-16}$

The similarity between the clinical phenotypes found in conjunction with these $\alpha$ tropomyosin mutations is surprising. Alternatively, the similar results of these mutations may reflect a common intracellular mechanism by which dysfunctional thin filaments trigger cellular hypertrophy.

We found three $\alpha$-tropomyosin gene mutations in 60 Japanese patients with familial HCM. These mutations were characterised by hypertrophy of the left ventricle which then progressed to the dilated phase and a high incidence of sudden or disease-related death.

This study was supported in part by a Grant-in-Aid for Scientific Research from the Ministry of Education, Science, and Culture of Japan and by grants for the study of cardiomyopathy from the Ministry of Health and Welfare of Japan and from the Japan Cardiovascular Research Foundation.

We thank Ms Y Yamaguchi for her excellent secretaria assistance.

1 Watkins $\mathrm{H}$, MacRae C, Thierfelder L, Chou Y-H, Frenneaux M, McKenna W, et al. A disease locus for familial hypertrophic cardiomyopathy maps to chromosome 1q3. Nature Genet 1993;3:333-7.

2 Carrier L, Hengstenberg C, Beckmann JS, Guicheny P, Dufour C, Bercovici J, et al. Mapping of a novel gene for familial hypertrophic cardiomyopathy to chromosome familial hypertrophic cardiomy
11. Nature Genet 1993;4:311-3.

3 Jarcho JA, McKenna W, Pare JAP, Solomon SD, Holcombe RF, Dickie $S$, et al. Mapping a gene for familial hypertrophic cardiomyopathy to chromosome 14q1 N Engl F Med 1989;321:1372-8.

4 Thierfelder L, MacRae C, Watkins $H$, Tomfohrde J, Williams M, McKenna W, et al. A familial hypertrophic cardiomyopathy locus maps to chromosome 15q2. Proc Natl Acad Sci USA 1993;90:6270-4.

5 Thierfelder L, Watkins H, MacRae C, Lamas R, McKenna $\mathrm{W}$, Vosberg H-P, et al. $\alpha$-Tropomyosin and cardiac troponin $T$ mutations cause familial hypertrophic cardiomyopathy: A disease of the sarcomere. Cell 1994;77:701-2.

6 Watkins H, Anan R, Coviello DA, Spirito P, Seidman JG, Seidman CE. A de novo mutation in $\alpha$-tropomyosin that causes familial hypertrophic cardiomyopathy. Circulation 1995;91:2302-5.

7 Watkins H, McKenna W, ThierfelderL, Suk HJ, Anan R, O'Donoghue A, et al. Mutations in the genes for cardiac troponin $\mathrm{T}$ and $\alpha$-tropomyosin in hypertrophic cartroponin $T$ and $\alpha$-tropomyosin in hypertrop
diomyopathy. $N$ Engl f Med 1995;332:1058-64.

8 Nakajima-Taniguchi C, Matsui H, Nagata S, Kishimoto T Yamauchi-Takihara K. Novel missense mutation in $\alpha-$ tropomyosin gene found in Japanese patient with hypertropomyosin gene found in Japanese patient with hyper-
trophic cardiomyopathy. $\mathcal{f}$ Mol Cell Cardiol 1995;27: trophic

9 Maron BJ, Gottdiener JS, Epstein SE. Patterns and signifcance of distribution of left ventricular hypertrophy in hypertrophic cardiomyopathy. A wide angle, two dimensional echocardiographic study of 125 patients. $\mathrm{Am} \mathcal{F}$ Cardiol 1981;48:418-28.

10 Nakajima-Taniguchi C, Matsui H, Eguchi N, Nagata S, Kishimoto T, Yamauchi-Takihara K. A novel deletion mutation in $\beta$-myosin heavy chain gene found in Japanese patients with hypertrophic cardiomyopathy. $\mathcal{F}$ Mol Cell Cardiol 1995;27:2607-12.

11 Yutani C, Imakita M, Ishibashi-Üeda H, Hatanaka K, Nagata S, Sakakibara H, et al. Three autopsy cases of progression to left ventricular dilatation in patients with hypertrophic cardiomyopathy. Am Heart $尹$ 1985;109. 545-53.

12 Nagata S, Park Y-D, Minamikawa T, Yutani C, Kamiya T, Nishimura $T$, et al. Thallium perfusion and cardiac enzyme abnormalities in patients with familial hypertrophic cardiomyopathy. Am Heart f 1985;109:1317-22.

13 Zot AS and Potter JD. Structural aspects of troponintropomyosin regulation of skeletal muscle contraction. tropomyosin regulation of skeletal muscle contra
Annu Rev Biophys Biophys Chem 1987;16:535-59.

Annu Rev Biophys Biophys Chem 1987;16:535-59.
14 Ruiz-Opazo N, Nadal-Ginard B. $\alpha$-Tropomyosin gene organization: alternative splicing of duplicated isotypeorganization: alternative splicing of duplicated isotype-
specific exons accounts for the production of smooth and specific exons accounts for the production of smooth and
striated muscle isoforms. $¥$ Biol Chem 1987;262:4755-65.

15 Takenaga $K$, Nakamura Y, Tokunaga K, Kageyama H, Sakiyama S. Isolation and characterization of a cDNA that encodes mouse fibroblast tropomyosin isoform 2 . Mol Cell Biol 1988;8:5561-5.

16 Hardy S, Fiszman MY, Osborne HB, Thiebaud P. Characterization of muscle and non-muscle Xenopus laevis tropomyosin mRNAs transcribed from the same gene. Developmental and tissue-specific expression. Eur $\mathfrak{f}$ Biochem 1991;202:431-40. 